\title{
Erratum zu: Was ist Tageslicht
}

\section{Erratum zu:}

Kapitel 1 in: R. Hammer und M. Wambsganß, Planen mit Tageslicht, essentials, https://doi.org/10.1007/978-3-658-30194-1_1

Die Originalversion dieses Kapitels wurde auf Seite 5 mit einer fehlerhaften Angabe veröffentlicht.

Dies ist nun korrigiert und lautet wie folgt:

Unter Tagesbedingungen und bei Leuchtdichten zwischen $0,001 \mathrm{~cd} / \mathrm{m}^{2}$ und $10^{4} \mathrm{~cd} / \mathrm{m}^{2}$ sind im menschlichen Auge die Zapfenrezeptoren in ihren drei Typen aktiv. 